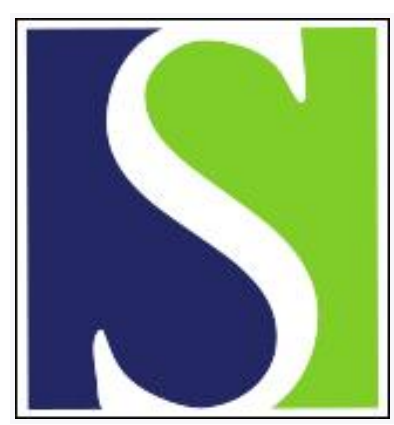

Scand J Work Environ Health 1989;15(4):302-304

https://doi.org/10.5271/sjweh.1849

Issue date: Aug 1989

A possible case of mercury-related toxicity resulting from the grinding of old amalgam restorations.

by Taskinen $\mathrm{H}$, Kinnunen E, Riihimaki V

Affiliation: Institute of Occupational Health, Helsinki, Finland.

This article in PubMed: www.ncbi.nlm.nih.gov/pubmed/2772585

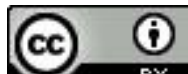




\title{
A possible case of mercury-related toxicity resulting from the grinding of old amalgam restorations
}

\author{
by Helena Taskinen, MD, Esko Kinnunen, MD, Vesa Riihimäki, MD, MSc ${ }^{1}$ \\ TASKINEN H, KINNUNEN E, RIIHIMÄKI V. A possible case of mercury-related toxicity resulting from \\ the grinding of old amalgam restorations. Scand J Work Environ Health 1989;15:302-304. The poten- \\ tial hazards of metallic mercury in dentistry are well recognized. The present report concerns a patient \\ who experienced an uncommonly high mercury exposure and, possibly, mercury-related toxicity from va- \\ por releaséd during extensive grinding of old amalgam fillings.
}

Key terms: amalgam, case report, mercury, poisoning.

The potential hazards of amalgam in dentistry have received considerable attention in recent times. In dental offices and elsewhere cases have been reported of poisoning by metallic mercury due to the careless handling and spillage of the metal $(1,2)$. In this paper we present a patient who had experienced uncommonly high mercury exposure and, possibly, mercury-related toxicity from vapor released during the extensive grinding of old amalgam fillings. We did not see the patient until one year after the treatment. The anamnestic information was gathered from the patient and from the notes of the physicians who had treated her.

\section{Case report}

A 60 -year-old woman was treated by a dentist during 12 visits over a period of 2.5 months (from 8 November 1985 through 22 January 1986). During the first two sessions two teeth earlier filled with amalgam were ground to the form of a bar to support a dental bridge. To improve occlusion, about $1 \mathrm{~mm}$ (measured from the occlusion models) was ground from the surface of 11 more amalgam-filled teeth, and three broken fillings were replaced during the following sessions. The dentist used a high-speed drill, water cooling, and aspiration.

One week after the beginning of the treatment the patient developed symptoms of stomatitis. Her lips and the mucous membranes of her oral cavity smarted, her tongue felt swollen, and salivation was strongly increased.

During the next week her throat became sore and did not improve with penicillin treatment. She felt an odd taste of rancid lard in her mouth, and her sense of smell weakened. She later suffered from dizziness and headache in the morning. Two months after the beginning of the treatment ( 6 January 1986) she felt

\footnotetext{
I Institute of Occupational Health, Helsinki, Finland.
}

Reprint requests to: Dr H Taskinen, Institute of Occupational Health, Topeliuksenkatu 41 a A, SF-00250 Helsinki, Finland. sharp pains in her thorax and had a temperature $\left(38.9^{\circ} \mathrm{C}\right)$ for a few days but no other symptoms of respiratory infection. The erythrocyte sedimentation rate (ESR) was $28 \mathrm{~mm} / \mathrm{h}$, but there were no actual abnormalities in her chest radiograph. The symptoms did not clearly respond to doxycycline treatment, and the woman's temperature remained slightly increased $\left(37.7^{\circ} \mathrm{C}\right)$ for three weeks. After one week the ESR was $26 \mathrm{~mm} / \mathrm{h}$ and remained unchanged for two months.

During the last month of the dental treatment the woman's sense of touch in her left hand and fingers weakened, her fingers became sensitive to cold, and her hand grip weakened. The toes of her left foot ached and had a tendency to cramp, and later the sense of touch became weaker in her foot. She had muscular twitchings of the upper lip and difficulties to remember things. Her general condition deteriorated, she felt unwell, and she lost $9 \mathrm{~kg}$ over the next few months. She also became anxious and depressed.

The patient was examined at the Institute of Occupational Health in December 1986, one year after the treatment. In the neurological examinations her tendon reflexes were weak, but symmetrical all over. Her senses of touch and pain were weakened in her fourth and fifth fingers and on the dorsum of the left hand and in the third, fourth and fifth toes of her left foot. The grip force of her left hand was also decreased.

In a repeated neurological examination by one of us (EK) in March 1987 the tendon reflexes of the woman's extremities were normal, as well as her senses of pain and vibration and her posture. Her sense of touch was weakened only in her left hand, but the motor function of her left ulnar nerve appeared normal. The patient responded to the scent of coffee but could not identify it. She could not recognize a salty or sweet taste.

Both in October 1986 and in March 1987 the electroneuromyographic findings of the upper and lower extremities were normal, as were the electroencephalograms made in May 1986 and March 1987. According to the neuropsychological examinations her cognitive 
capacity was good, but there was some impairment in motor performance. Especially the results of the "Mira" drawing test (3) were abnormal.

In the 1950s the patient had had severe lung tuberculosis, which was treated with induced left-sided pneumothorax. A current chest radiograph showed pleural thickening and fibrotic pulmonary changes, but no signs of congestive heart disease. The patient had received Digoxin $^{(\mathrm{R})}(125 \mu \mathrm{g} / \mathrm{d})$ and Furosemide ${ }^{(\mathrm{i})}$ (40 mg/d) since September 1985 because of mild dyspnea at that time. She had not earlier experienced chest pains similar to those that occurred after the dental treatment.

An analysis for urinary mercury was performed three months after the cessation of the dental treatment and was repeated during a follow-up period of almost a year (figure 1). The specimens were incorporated into routine sample series and analyzed with coldvapor atomic absorption spectrophotometry, which is regularly monitored by internal and external quality control procedures. After the second measurement, in May 1986, all the amalgam fillings were removed and replaced with gold fillings. This treatment was performed with extreme caution, with the aid of water cooling, aspiration, and protection of the oral mucosa.

\section{Discussion}

Three different routes for the uptake of mercury from amalgam have been proposed (4). A corrosion process liberates mercury ions which may reach the central nervous system from the dental pulp either along a venous or neural route. However, the content of mercury in trigeminal nerves has varied in different studies, and the significance of retrograde axonal transport so far seems obscure. Ingested mercury will be partly absorbed in the intestine. The most important route for the uptake of mercury from amalgam is the inhalation of mercury vapor released during dental filling procedures or the removal of old amalgam restorations. High mercury levels, up to about $1 \mathrm{mg} / \mathrm{m}^{3}$, have been measured in the breathing zone of a dentist, especially if water cooling and aspiration have been neglected (5). With adequate water cooling and aspiration the mercury concentration in the dentist's breathing zone was $0.11 \mathrm{mg} / \mathrm{m}^{3}(5)$. In the oral cavity of the patient the concentration may be considerably higher. By way of comparison, the hygienic standard (time-weighted average for $8 \mathrm{~h}$ ) for mercury in workroom air is $0.05 \mathrm{mg} / \mathrm{m}^{3}$ in many countries, including Finland (6).

Three months after the dental treatment our patient still had an abnormally high mercury concentration in her urine. The level of urinary mercury decreased during the observation period by a rate corresponding to a half-time of about two months, which is a value consistent with the recognized elimination rate of mercury from the body (6). Thus we can speculate that the mercury level in the patient's urine during treatment may have been somewhere in the range of $50-80 \mu \mathrm{g} / \mathrm{l}$.
This level per se would not normally be regarded as high enough, among long-term exposed workers, to imply a significant risk of symptomatic mercury toxicity. However, the dental treatment in this case constituted a pattern of repeated intensive acute exposures which may have enhanced local effects and the distribution of mercury in the brain. A high-speed watercooled drill was used, and aspiration was applied. The grinding process was, however, exceptionally extensive, and, as a result of repetitive procedures, mercury may have accumulated to toxic levels. In the occupationally unexposed Finnish population the average urinary mercury level is less than $10 \mu \mathrm{g} / \mathrm{l}$ with an average of $3-5 \mu \mathrm{g} / 1$ (7).

The early effects of long-term exposure to mercury vapor are nonspecific. A symptom complex encompassing fatigue, general weakness, anorexia, diarrhea, and loss of weight is called asthenic vegetative syndrome or "micromercurialism"' (8). Early subjective symptoms, performance changes on behavioral tests, and a change in spontaneous tremor frequency appear at an increasing rate when the concentration of mercury in urine reaches $50-100 \mu \mathrm{g} / \mathrm{l}(6)$. Higher levels of mercury cause behavioral and psychological changes such as irritability, memory disturbances, insomnia, excessive shyness, depression, and, in extreme cases, even delirium and hallucinations (9). This syndrome is called erethismus mercurialis. Typical neurological symptoms of mercury toxicity are intention tremor of the hands and muscular twitchings of the eyelids and lips. Very high concentrations of inhaled mercury have caused chemical pneumonitis (9).

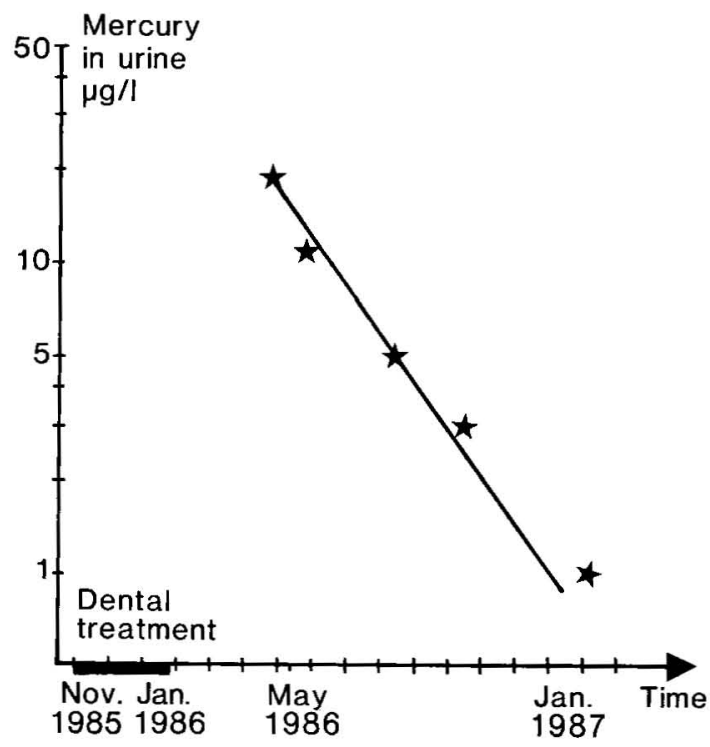

Figure 1. Mercury concentration in the morning urine samples, corrected for specific gravity, after the dental treatment. The straight line, fitted to the points by the least squares method, corresponds to an elimination half-time of approximately $60 \mathrm{~d}$. 
In the behavioral tests our patient showed impairment of certain qualities of motor performance reminiscent of changes found among mercury-exposed workers. Her symptoms seemed more severe than what could be expected from the measured urinary mercury levels. The effects of a series of high acute exposures may be different from those of the long-term exposure. On the other hand it needs to be stressed that many of the symptoms and signs of mercury poisoning are subjective and nonspecific, and thus the diagnosis in single cases is circumstantial. It is possible that some parts of the symptom complex of our patient were due to other causes.

The patient had earlier experienced transient numbness in her upper extremities. The neurological symptoms and signs of her left hand might also be explained by degenerative changes in the cervical spine. The patient's thoracic symptoms and high temperature are also somewhat puzzling as no certain clinical diagnosis could be reached at the time. It is known that exposure to mercury vapor can cause acute bronchitis, bronchiolitis, pneumonia, and fever (6).

The symptoms of our patient correspond to those described in the literature under the clinical syndrome micromercuralism caused by mercury exposure ( 8 ). The changes in the senses of smell and taste, which in this case appeared to be particularly vulnerable to mercury toxicity, would suggest a mechanism of axonal flow of mercury through the olfactory nerve from the nasal cavity (10).

Our case indicates a potential risk of mercury vapor exposure both for patients and dentists during extensive grinding of amalgam restorations. Such operations need to be carefully planned from the work hygiene point of view to guarantee the safety of both the patient and the dentist. High-volume aspiration is essential, in addition to effective water-cooling of the drill. If excessive exposure is nevertheless anticipated, it can be assessed by urinary mercury measurements. Multiple nonspecific symptoms and minor objective signs may cause great difficulties in the differential diagnostics, and therefore an objective verification of potentially hazardous exposure is an important criterion.

\section{References}

1. McNeil NI, Issler HC, Olver RE, Wrong OM. Domestic metallic mercury poisoning. Lancet 1984;1:269-71.

2. Smart ER. The hazards of mercury in dentistry. Rev Environ Health 1985;1:60-86.

3. Hänninen $\mathrm{H}$, Lindström K. Behavioral test battery for toxicopsychological studies used at the Institute of Occupational Health in Helsinki: reviews 1. Helsinki: Institute of Occupational Health, 1979.

4. Pleva $\mathbf{J}$. Mercury poisoning from dental amalgam. J Orthomolec Psychiatry 1983;3:184-93.

5. Richards JM, Warren PJ. Mercury vapour released during the removal of old amalgam restorations. $\mathrm{Br}$ Dent J 1985;159:231-2.

6. Skerfving S, Berlin M. Nordiska expertgruppen för gränsvärdesdokumentation 59: oorganiskt kvicksilver [Inorganic mercury: Nordic expert group for documentation of occupational exposure limits]. Solna (Sweden): Arbetarskyddsstyrelsen, 1985. (Arbete och hälsa 20.)

7. Aitio A, Valkonen S, Kivistö H, Yrjänheikki E. Effect of occupational mercury exposure on plasma lysosomal hydrolases. Int Arch Occup Environ Health 1983;53: 139-47.

8. Friberg L, Nordberg GF. Inorganic mercury - relation between exposure effects. In: Friberg L, Vostal J, ed. Mercury in the environment. Cleveland, $\mathrm{OH}$ : CRC Press, 1972.

9. Klaassen CD. Heavy metal and heavy metal antagonists. In: Goodman Gilman A, Goodman LS, Rall TW, Murad F, ed. Goodman and Gilman's the pharmacological basis of therapeutics. New York, NY: Macmillan Publishing Company 1985:1605-27.

10. Nilner K, Ákerman S, Klinge B. Effect of dental amalgam restorations on the mercury content of new tissues. Acta Odontol Scand 1985;43:303-37.

Received for publication: 28 December 1988 